\title{
Arqueologia com Sentidos. Uma Introdução à Arqueologia Sensorial
}

José Roberto Pellini ${ }^{1}$

jrpellini@gmail.com

Resumo: Somos seres encorpados, sendo assim, nossa experiência do dia a dia é uma experiência sensorial. Captamos as informações do mundo através dos sentidos. Cores, texturas, aromas, paladares, a sensação de movimento, de calor, de peso, tudo nos é apresentado através dos sentidos, sendo assim, entender como concebemos historicamente os sentidos nos permite entender como concebemos o mundo à nossa volta. A Arqueologia Sensorial busca entender como através da experiência sensorial com a materialidade, construímos nossas histórias, identidades, políticas, cultura e memórias. .Palavras-Chave: Arqueologia Sensorial, Sentidos, Teoria, Interpretação, Ocularcentrismo

Abstract: Summary: We are bodiedbeings, so, ourexperienceofeverydaylifeis a sensoryexperience. We capture theworld'sinformationthroughthesenses. Colors, textures, smells, tastes, thesenseofmovement, heat, weight, everythingispresentedtousthroughthesenses, therefore, understandhowhistoricallyconceivedthesensesallowsustounderstandhowwe design the world around us. SensoryArchaeologyseekstounderstandhowthroughsensoryexperienceofmateriality, wehavebuiltourstories, identities, policies, cultureand memories.

Keyworlds: Sensorial Archaeology, Senses, Theory, Interpretation, Ocularcentrism

Resumen: Somos seres concuerpo, así, nuestraexperiencia de la vida cotidiana es una experiencia sensorial. Capturamos lainformacióndel mundo a través de los sentidos. Colores, texturas, olores, sabores, lasensación de movimiento, el calor, el peso, todo se nos presenta a través de los sentidos, por lo tanto, comprendercómohistóricamenteconcebimoslos sentidos nos permite entender cómodiseñamosel mundo que nos rodea. Sensorial Arqueología busca entender cómo a través de laexperiencia sensorial de lamaterialidad, hemosconstruidonuestra historias, identidades, las políticas, la cultura y losrecuerdos.

Palabras clave: Arqueología Sensorial, Sentidos, Interpretación, Ocularcentrismo

${ }^{1}$ Laboratório de Arqueologia Sensorial. Universidade Federal de Sergipe.

( Rev. Arqueologia Pública

\begin{tabular}{l|l} 
Campinas, SP & v.
\end{tabular}

No.()

p.1-12

12015

ISSN 2237-8294 
Campinas, 23 de Março de 2015. Acabo de descer do ônibus. Estou um tanto perdido. Nunca estive na UNICAMP e parece que desci antes do que deveria. Mas isso não é um problema, pois adoro caminhar. Ao sentir o mundo com meus pés fico mais conectado com meu entorno, com meu corpo. Minhas ansiedades e angústias se dissipam e meu pensamento se torna mais claro. Quando ando de carro tudo é distante, intocável, controlado. Os sons são artificiais, o tempo corre mais rápido, a pressa domina. Ao caminhar tudo muda. As distancias aumentam, o tempo se dilata, e tudo parece tangível. Esquadrilho o mundo com a força de minhas pernas. Dito meu próprio ritmo e deixo de ser refém deste mundo já anestesiado. Mais importante de tudo é que ao caminhar dou a oportunidade para que o mundo me surpreenda. A cada passo, a cada esquina, um novo som, um novo aroma, uma nova textura pode me arrebatar, ainda mais com esta luz difusa e tranquila do final do verão. O outono sempre foi minha estação favorita. Se no verão tudo é intenso e agitado, no outono é diferente. O mundo parece mais calmo, mais interiorizado e contemplativo. Sigo andando por uma grande avenida e o que me chama a atenção é que há muito verde por todos os lados. Mais parece que estou caminhando em um parque e não em uma malha urbana. O dia está ensolarado e uma brisa tranquila toca meu rosto. O que me chama mais atenção é a luz, que difusa por entre as árvores já parece anunciar o fim do verão. Tenho vontade de deitar no gramado e ficar aqui vendo as nuvens passar. Quando eu era criança passava boa parte do meu tempo olhando e dando formas para as nuvens. Era um mundo rico em fantasias. Mas crescemos e temos que abandonar estas práticas, pois dizem que somos adultos. E por falar em ser adulto, acabo de cruzar os portões da UNICAMP. Estou animado para o minicurso de Arqueologia Sensorial, pois é mais uma oportunidade de difundir este campo de estudo ainda novo na Arqueologia, mas já bastante carregado de pré-conceitos. Eu mesmo fui alvo de piadas quando, no Congresso da Sociedade de Arqueologia Brasileira de 2013, em Sergipe, coordenei junto com Andrés Zarankin um simpósio sobre o tema. Nos corredores éramos chamados de "os sensoriais" ou "os emocionais" de modo jocoso. Não tenho dúvidas de que parte das críticas à Arqueologia Sensorial, pelo menos no Brasil, se deve fundamentalmente à falta de informação. Há ainda pouca divulgação, pouca gente que trabalha dentro desta área aqui no Brasil. Ao mesmo tempo, tenho que considerar que a Arqueologia Brasileira é ainda 
muito conservadora, fechada e presa aos pressupostos histórico-culturalistas. Confesso que o nome "Sensorial" ou "dos Sentidos" não ajuda muito. Dá a impressão de algo etéreo, emocional ou mesmo místico. Imagina isso na cabeça de um positivista. É claro que acaba virando piada. Meus alunos têm sentido isso na pele, mesmo querendo trabalhar e explorar este campo, eles sentem-se receosos e com medo das brincadeiras e das provocações: isso não é Ciência!!!

Imaginem jovens pensadores, ainda inseguros, tateando o mundo, escutando daqueles que tem por tarefa educá-los coisas como estas. É frustrante, pois a autoridade acadêmica acaba por castrar o desejo pelo novo. Mas hoje, caminhando pelos bosques, chego à conclusão de que os críticos têm razão. Se pensarmos no modelo oitocentista de ciência, com seu distanciamento e estruturas de poder hierarquizadas, realmente tenho que aceitar, com certo sarcasmo, que a Arqueologia Sensorial não é ciência, mas um estilo de vida!!! Estilo de vida questionador e inquieto. Brinco que a Arqueologia Sensorial é quase uma espécie de terapia que nos desperta de nossa anestesia, nos torna mais conscientes dos ritmos do dia a dia, de nossa educação, de nossos comportamentos e disposições.

Mas sejamos práticos José (adoro falar comigo mesmo como se fosse uma terceira pessoa!!!). Se um aluno daqui a algumas horas lhe perguntasse como você define a Arqueologia Sensorial e você falasse que é um estilo de vida, convenhamos; ele provavelmente iria rir da sua cara, levantar e ir embora. Concordo. Eu começaria então falando o que a Arqueologia Sensorial não é. Isso ajuda a desmistificar o tema e, sendo assim, eu diria que a Arqueologia Sensorial não é uma tentativa de reconstruir o passado e a experiência sensorial do passado, ela não é uma tentativa para entender o sentir ou como as pessoas sentiam no passado, muito menos é uma tentativa de reproduzir no presente as sensações passadas. (HAMILAKIS, 2012). A Arqueologia Sensorial não tenta trazer de volta as emoções sentidas. A Arqueologia Sensorial não tenta saber ou reproduzir, por exemplo, o gosto da carne ou do pão no Egito Antigo, o som das harpas na Grécia Clássica ou o cheio do perfume do incenso que era utilizado nas cerimônias religiosas na Basílica de Santa Sofia no século VI em Constantinopla. O que a Arqueologia Sensorial tenta entender é como o paladar do pão ou da carne, o som da harpa e o cheiro do incenso, nestes exemplos, estruturavam realidades de mundo específicas, ou seja, como, através dos sentidos, realidades, identidades e memórias eram criadas.

(c) Rev. Arqueologia Pública

\begin{tabular}{l|l} 
Campinas, SP & v.
\end{tabular}

No.()

p. 1-12

$/ 2015$

ISSN 2237-8294 
Para mim, a Arqueologia Sensorial é a mais básica das Arqueologias. Somos seres encorpados, sendo assim,nossa experiência do dia a dia é uma experiência sensorial. Captamos as informações do mundo através dos sentidos. Cores, texturas, aromas, paladares, a sensação de movimento, de calor, de peso, tudo nos é apresentado através dos sentidos. Entre nós humanos, não há nada mais básico do que nossa relação sensorial com as materialidades do mundo. Os sentidos representam o domínio mais fundamental de nosso engajamento com o mundo, o meio pelo qual todos os valores e práticas são performados. Mesmo nossas memórias são criadas e ativadas através de nossa relação sensorial encorpada com o mundo material. Se vivenciamos o mundo através dos sentidos, precisamos entender como pensamos e estruturamos os sentidos, para assim entendermos como vivenciamos o mundo à nossa volta.

O problema é que as pessoas no Ocidente, acreditam, ou melhor, foram educadas e ensinadas a acreditar, que os sentidos são apenas uma ferramenta fisiológica para a captação dos estímulos do mundo. Desde pequenos somos educados e condicionados a não tocar algumas coisas, a não ver outras, a não prestar atenção em certos sons, a nos afastarmos de certos aromas, ou seja, desde pequenos somos submetidos a situações sociais que vão educando nossos sentidos e nosso comportamento. Somos ensinados a lidar com nossos sentidos, a confiar neles ou não enquanto fonte de informação. Nós no ocidente confiamos mais na visão como fonte de verdades do que qualquer outro sentido. A maneira pela qual os sensos são educados criam estruturas para ação e interpretação do mundo que oferecem e regulam possibilidades aos indivíduos. Hoje nos parece natural afirmar que a visão é o mais desenvolvido dos sensos. Desde Aristóteles (2010), fomos ensinados que a visão é o senso superior, fonte da razão e sinônimo da verdade e do conhecimento. Santo Agostinho (2002), seguindo a tradição aristotélica, também destacava a visão dentre os demais sensos, assim como Descartes (1965), para quem a visão era o mais nobre e universal dos sentidos.

Mas houve uma época no Ocidente em que a visão foi tratada como uma ameaça. Durante a Idade Média, havia na Europa a crença de que era pelo olhar que as bruxas agiam. Kramer e Sprenger, inquisidores e autores do MaleusMalleficarum, ao listarem os meios pelos quais as bruxas agiam, dedicaram especial atenção ao olhar. Pedro Ciruelo, preceptor de Felipe II, rei da Espanha entre 1556 e1598, também associava a prática do mal olhado às bruxas e ao Demônio. Em ambos os casos, a visão é tida como veículo para o mal, ou seja, transcende seu papel como ferramenta fisiológica.

(C) Rev. Arqueologia Pública

Campinas, SP $\quad$ v.

No.()

p. 1-12

$/ 2015$ ISSN 2237-8294 
Ao mesmo tempo, houve tambémquem defendesse o tato, normalmente visto como o mais inferior dos sentidos. Hans Cristian Andersen, o grande dinamarquês autor de contos de fada, atribuía mais importância ao tato para a identificação das verdades do mundo do que para a visão. Em sua obra a Princesa e a Ervilha, por exemplo, é a acuidade tátil que revela a verdadeira natureza das pessoas. O tato também foi defendido por Benedetto Varchi em seu Duelezione. Varchi acreditava que o tato era mais confiável que o senso da visão e, por isso, uma escultura era algo mais verdadeiro do que uma pintura (MOSHENSKA, 2011).

No período medieval, os sentidos eram pensados por seu caráter moral e não funcional. Assim, Santo Agostinho (2002), por exemplo, pensava nos sentidos como portas para o pecado. As hagiografias monásticas também evidenciam a relação entre os sentidos e a ideia de pecado. O objetivo era lembrar o devoto dos perigos e habilidades do demônio em ludibriar os sentidos a fim de instigá-los ao pecado (NEWHAUSER, 2012). Foi enganando os sentidos que o Demônio teria colocado um copo de prata no deserto diante de Antônio do Egito, para que esse cometesse o pecado da avareza, ou que teria se disfarçado de Cristo para levar Martim de Tours a cometer o pecado do orgulho.

A ideia de que temos apenas cinco sentidos também é uma construção que remonta a Aristóteles (2010), embora o primeiro a nomear os cinco sentidos no Ocidente tenha sido o grego Demócrito. Constance Classen, em Inca CosmologyandtheHumanBody (1993), demonstrou que nem todas as sociedades apresentam a mesma divisão aristotélica dos sentidos como no Ocidente. Por exemplo, enquanto os javaneses dividem seus sentidos em visão, audição, olfato, sentimento e fala, os Cashinahua do Peru classificam os sentidos em pele, mão, ouvido, genitália, fígado e olhos. Mesmo no Ocidente, o modelo aristotélico não passou sem críticas. Tomkins, autor de teatro, em sua obra Lady Língua e a Batalha dos Cinco Sentidos de 1607, defendia a inclusão da fala enquanto sentido. Me debruçando nos últimos meses sobre as leis germânicas do período medieval, principalmente sobre as listas de compensação por injúria, pude perceber que, entre os povos germânicos, danos causados por terceiros à fala e ao tato resultavam em uma compensação monetária maior que a compensação destinada para a perda da visão.

Antes de serem apenas uma simples diferença semântica em relação ao modelo ocidental dos sentidos, tais modelos sensoriais têm implicações práticas no dia a dia. Consideremos, por exemplo, o caso dos Ongees, povo caçador-coletor da Baía de Bengala. Para eles, as paisagens são formadas por odores. Diferente de nós no Ocidente, que 
mapeamos o mundo através das informações visuais, os Ongees mapeiam seu entorno através dos diferentes odores da paisagem e, assim, ordenam tempo e espaço através do ciclo anual de aromas(PANDYA, 1993). Pense agora no trabalho do arqueólogo. Vamos para campo e resolvemos mapear o território Ongee. Ligamos nosso GPS, nossa Estação Total, coletamos coordenadas geográficas e desenhamos mapas. No fim do dia voltamos para casa com a nítida impressão de que sabemos os limites e a definição do território Ongee. Nada mais errado. Mas alguém poderia perguntar: e se coletássemos a coordenada geográfica de um determinado aroma? O problema é que nossa representação de espaço através de mapas é estática, enquanto o mundo Ongee é dinâmico. Odores mudam com o clima, com as estações, sendo assim, como mapear algo com tamanho dinamismo?

Odor também é importante para os Desana da Colômbia, que diferenciam as suas cestarias de acordo com o odor da palha (VAN EDE, 2009). E aqui vale a pena pensar de novo no papel do arqueólogo. Normalmente classificamos a cultura material através de pistas visuais, ou seja, reunimos aquilo que se assemelha em forma, decoração e estilo. Tal sistema não teria sentido algum entre os Desana, simplesmente porque eles, diferente de nós, não ordenam seu mundo através de formas visuais e sim de manifestações odoríficas. De que adianta ordenar todas as cestarias Desana segundo tamanhos, formas, cores e desenhos diferentes, se o que importa para eles é o odor da matéria prima?

Outro bom exemplo é o caso da fotografia, que no Ocidente é vista como representando uma cópia do real. Recentemente estive em Versailhes e vi uma cena que para mim foi chocante. Estava no quarto que pertenceu a Napoleão e enquanto eu gastava cada minuto disponível tentando vivenciar aquele lugar, capturando cada som, cada imagem, cada odor presente no espaço, pude ver um rapaz com uma filmadora na mão, passando apressado sem mesmo olhar para o quarto. Segui-o à distância, pois achei curioso aquele comportamento. Sua atitude era sempre a mesma, seguindo rápido pelos aposentos do Palácio, sempre olhando para frente e com a câmera direcionada para o ambiente. Era mais importante para ele capturar em imagens o ambiente, para depois provavelmente postar nos Facebooks e nos Instagrans, do que vivenciar o lugar e, assim, criar memórias sobre ele. Nossa sociedade se transformou em uma sociedade do espetáculo, onde a vivência e a experiência deram lugar à observação distanciada das câmeras e filmadoras.

Mas há locais onde fotografar ou mesmo filmar não produz os resultados esperados na captura das essências. Por exemplo, os vitrais das igrejas Bizantinas, ao refratarem a luz 
natural, criam uma sensação de movimento e presença que se modifica de acordo com nosso próprio movimento. Quando estive na Santa Sofia em Istambul, pude vivenciar o mosaico de ChristoHagios me seguindo por onde eu ia. Fotografei diversas vezes e em diversas posições. Filmei mais de 10 minutos em movimento e percebo hoje, revisitando as fotos e filmes, que a sensação de movimento das imagens e a sensação de presença se esvaem. Sabe por quê? Porque eles não foram feitos para serem fotografados, desenhados, e sim vivenciados.

Outro bom exemplo de algo que não é criado para ser transformado em uma imagem estática é a pintura de areia Navarro. A pintura de areia entre os povos Navarro faz parte de um ritual de cura que tem como principio aprisionar o espírito causador da doença. Conforme a pintura de areia é feita, o espírito maléfico vai sendo aprisionado. No final, a pintura é destruída, pois os navarros acreditam que com este gesto se destrói também o espírito maligno. Agora imagine um ocidental frente à pintura Navarro. É muito provável que diante da beleza da pintura ele saque sua potente câmera e fotografe sem parar até que seu cartão de memória esteja cheio. O que ele talvez não saiba é que junto com as fotos ele guardará de recordação o espirito maléfico e, assim, o doente não poderá ser curado. Pensemos mais uma vez no caso da arqueologia. Aqui vale uma provocação: será que devemos tratar as imagens em sítios rupestres apenas como imagens? Tirar fotos, filmar, fazer decalques e levar tudo digitalizado para nosso computador? Cuidado, pois, podemos estar levando para casa algo mais do que apenas imagens!!!

Através dos sentidos não apenas nos relacionamos com o mundo, nós estabelecemos estruturas de sociabilidade. Em geral, hierarquias sensoriais estão associadas às hierarquias sociais, sendo empregues para ordenar as sociedades. Grupos dominantes tendem a estar ligados aos sensos mais estimados, enquanto os grupos subordinados normalmente estão ligados aos sensos menos privilegiados. Por exemplo, no século 19, o naturalista Lorenz Oken, postulava uma hierarquia racial dos sentidos, onde os africanos apareciam associados ao tato, os australianos e melanésios ao paladar, os nativos americanos ao olfato, os asiáticos à audição e os brancos europeus apareciam associados à visão.

As hierarquias sensoriais não dizem respeito apenas à construção das raças, mas também às construções de gênero. No mundo oitocentista Ocidental, o homem estava associado aos sentidos superiores da visão e da audição, enquanto as mulheres estavam associadas aos sentidos do tato, do olfato e do paladar. Cabia ao homem atividades como 
estudar, viajar, governar, enquanto às mulheres cabia atividades mais ligadas ao lar, como a nutrição, a reprodução e os cuidados com as pessoas. Considerava-se que as mulheres tinham baixa acuidade visual e auditiva, o que as tornava inaptas para o trabalho intelectual, que supunha a visão para ler e a audição para discutir. Tais classificações sensoriais ainda têm uma enorme força social, desde que até hoje escritoras, artistas e mesmo arqueólogas têm que justificar o porquê de fazerem atividades consideradas como masculinas, ao invés de se dedicarem a atividades como cozinhar e cuidar da casa. Nas ruas de São Paulo não é incomum ouvir um homem mandando uma mulher ir cuidar das crianças ou da comida do marido porque ela cometeu um erro no trânsito.

Ao mesmo tempo, quem nunca sentiu certo desconforto quando em uma fila de banco ou em um ônibus lotado sentiu um odor forte de suor? Classen (1993b) tem demonstrado como na modernidade o odor do outro frequentemente serve como um bode expiatório para certas antipatias sociais, especialmente quando um membro de uma cultura classifica o odor do outro como ofensivo. Neste sentido, o olfato pode funcionar como um poderoso índice de diferença racial, por exemplo, como demonstrou Manalansam (2006) em sua análise da etnografia olfativa de Nova York. A classificação de um odor como ruim está sempre acompanhada de um julgamento moral contra as pessoas, os objetos e lugares. Quando George Orwell retratou as divisões de classe no mundo ocidental no inicio do século 20, ele escreveu: “... o real segredo da divisão de classes no ocidente pode ser resumido pelo mal cheiro da classe inferior." Ao taxar a classe trabalhadora como fétida, a burguesia europeia não só aumentava a consciência da associação entre odores e classes, como também personificava os odores.

Rhys-Taylor (2010) nos conta um caso singular, o da reordenação sensorial da área do Spitalfields Market na zona leste de Londres. Em busca de uma maior valorização para o bairro e com a vinda de novos investidores para a região, o mercado foi sistematicamente combatido através de discursos sensoriais excludentes. A estratégia opunha o mercado livre de rua, com sua suposta desorganização, insegurança, aromas e paladares abjetos e poluição sonora vinda da concentração de pessoas, às lojas de departamento, com seu espaço organizado, controlado, seguro, onde os sons eram padronizados com o uso de músicas calmas e de baixo volume. O que se buscava na realidade era adequar o espaço urbano aos modelos sensoriais normativos da elite inglesa a fim de possibilitar o afluxo de novos investidores. Como defende a autora, a sensibilidade hegemônica que os planificadores 
urbanos defendiam neste caso, perpetuava traços fenomenológicos de racismo. Cheiros, aromas, sabores, texturas não normativos ou desconhecidos passaram e foram interpretados como um símbolo de inferioridade moral, cultural e mesmo biológica. A despeito de haver uma adequação às políticas visuais em relação à admissão de pessoas de diferentes raças em áreas públicas das cidades, que estão de acordo com as políticas anti-racistas, a maneira pela qual os usuários dos mercados estavam classificando olfato e paladar eram aspectos centrais para a continuidade das políticas de discriminação. O racismo aqui se desloca da pele para 0 paladar e o olfato do outro.

O que são estas categorizações que assinalam e fixam a partir da cor da pele, da forma do corpo, do tipo facial, do cheiro, do som, do olfato, senão ferramentas sensoriais que servem apenas para definir o eu e o outro? A própria invenção da ideia de sociedade primitiva habilitou os europeus a definirem sua própria modernidade a partir da imaginada desordem e falta de regulação sensorial das sociedades coloniais. Os sentidos, neste caso, representam a antítese da cultura e da sociedade.

Eu mesmo que trabalho com a temática dos sentidos já fui pego por estas construções. Quando eu entrei na Federal de Sergipe, tive que fazer uma centena de exames. Quem já passou em um concurso público sabe do que estou falando. Para ganhar tempo, me dirigi a uma clínica particular. Logo que entrei na clínica fiquei maravilhado. Chão de mármore, cheiro de pinho, paredes bem acabadas e com tinta nova, bancos de couro acolchoados, quase nenhum barulho, a não ser o das pessoas conversando baixo, atendentes com a roupa impecavelmente branca, usando luvas e touca. Me senti seguro. Fiz todos os exames de que precisava, menos o raio- $X$ do pulmão, pois este necessitava de um pedido especial e, como não havia médicos naquele momento, me indicaram ir até um posto do SUS e pegar um pedido para a realização do raio-X. Logo que cheguei ao SUS, meu corpo foi instintivamente se retraindo. Paredes mofadas e mal pintadas, sujeira por todos os lados, cadeiras quebradas, mas o pior ainda estava por vir, o balcão de atendimento. Eu mal conseguia me aproximar daquela fórmica amarelada e lascada. Tinha a impressão de que se tocasse no balcão meu braço iria cair. Minha esposa Carol ria ao me ver todo contraído. Só neste momento é que me dei conta do que estava fazendo, reproduzindo um discurso que associa sujeira, pobreza e doenças para distanciar o eu e o outro. Este discurso foi utilizado, por exemplo, para justificar a reurbanização de cidades como Paris no século 19 e Rio de Janeiro e Valparaíso no início do século 20.

(C) Rev. Arqueologia Pública

\begin{tabular}{l|l} 
Campinas, SP & $\mathrm{v}$.
\end{tabular}

No.()

p. 1-12

/2015

ISSN 2237-8294 
Todos estes exemplos nos mostram claramente que não somente os sentidos ultrapassam a esfera fisiológica, como a ideia de que temos apenas cinco sentidos é uma construção cultural. Se pensarmos que a maneira pela qual as pessoas pensam os sentidos determina o modo como elas vão se relacionar com o mundo à sua volta, precisamos urgentemente reavaliar nossa prática arqueológica, pois, ao insistirmos nos modelos visualistas, estamos pressupondo que o outro pensa como nós e, sendo assim, eliminamos a possibilidade do outro de pensar diferente. Se reconhecemos que nem todas as culturas compartilham o modelo sensorial adotado no Ocidente, devemos considerar práticas arqueológicasque vão além do visualismo analítico que caracteriza nossa disciplina. Como ressalta Viveiros de Castro (2003), no mundo Ocidental, o comprometimento ontológico do outro tem sido convertido em epistemologias, ou seja, a ontologia do outro passa a ser apenas uma representação equivocada, fragmentada e parcial de nossa ontologia ocidental. Ele nos lembra que não importa se as crenças são verdades ou não, mas que as pessoas atuam com base em suas verdades, em suas visões de mundo, em suas ontologias. Um avanço ontológico na arqueologia só será possível se pensarmos nas teorias indígenas mais seriamente como ontologias, antes que epistemologias. Pensar que existe uma universalidade do corpo e das experiências sensoriais impede que consideremos variações da significação da experiência perceptiva, assim como nos impede de pensar mundos e ontologias alternativas. Ao mesmo tempo, isto nos induz a pensar que nossa experiência ocidental de mundo é a norma.

Como defende Howes (2005), a revolução sensorial nas Ciências Humanas não diz respeito apenas a colocar o corpo e os sensos em evidência através de relatos evocativos da vida corporal, mas de analisar as ideologias sociais concebidas através dos valores e práticas sensoriais. Os sensos não são apenas mais um campo de estudos como gênero, colonialismo ou cultura material, os sensos são o meio através do qual nós experimentamos e damos sentido ao gênero, à cultura material e ao colonialismo. Ao trabalhar com os sentidos temos a possibilidade de romper com o contínuo político e ideológico que nos coloniza e nos faz perpetuar hierarquias senso-raciais, discursos de poder e visões de mundo específicas. Para Hamilakis (2012), talvez o principal potencial da Arqueologia Sensorial seja sua capacidade de reformular o próprio campo da Arqueologia, libertando a disciplina e os próprios arqueólogos de suas correntes modernistas e ocularcentristas, ao adotar uma prática multissensorial e 
mnemônica, e é justamente por isso que para mim muito mais do que ciência, a Arqueologia Sensorial é um estilo de vida!

Bibliografia:

AGOSTINHO. A Cidade de Deus. $7^{a}$ ed. Trad. Oscar Paes Lemes. Rio de Janeiro, Editora Vozes, 2002.

ARISTÓTELES. Da Alma (De Anima). Trad. Ana Maria Lóio. Lisboa, Imprensa Nacional Casa da Moeda. 2010

CLASSEN, C. Inca CosmologyandtheHumanBody. Salt Lake City: Universityof Utah Press. $1993 a$

CLASSEN, C. Worlds ofSense: ExploringtheSenses in HistoryandacrossCultures. London and New York: Routledge. 1993b.

DESCARTES, R. DiscourseonMethod, Optics, Geometry, andMeteorology. Trans. Paul J. Olscamp. Indianapolis: Bobbs-Merrill, 1965.

HAMILAKIS, Y. Afterword: Eleven Theses on the Archaeology of the Senses. In: DAY, J. (Ed.). Making Senses of the Past: Toward a Sensory Archaeology. Center for Archaeological Investigations, Occasional Paper n. 40: 409-419. 2012.

HOWES, D. Empire ofSenses: The Sensual Culture Reader. Berg, Oxford. 2005

MANALANSAN, M. ImmigrantLivesandthePoliticsofOlfaction in the Global City. In:

Drobnick, J. (ed.) The SmellCulture Reader, Oxford, Berg, 2006. p 41-52

MOSHENSKA, J. Feeling Pleasures: The SensesofTouch in RenaissanceEngland. A DissertationPresentedtotheFacultyof Princeton University in Candidacy for theDegreeofDoctorofPhilosophy. DepartmentofEnglish. New Jersey. 2011. 


\section{ATAS}

NEWHAUSER, RTheseSeavenDevil's: The Capital Vices onthe Way toModernity. In: NEWHAUSER, R.; RIDYARD, S. (Eds.). Sinin Medieval na EarlyModerneCulture. The TraditionofseavenDeadley Sins. New York: York Medieval Press. 2012, p. 157-190.

PANDYA, V. Abovethe Forest: A StudyofAndamaneseEthnoanemology, Cosmology, andthe Power of Ritual. Delhi: Oxford University Press. 1993.

RHYS-TAYLOR, A. ComingtoSenses: A MultisensoryExplorationsofClassandMulticulture in East London. Thesissubmitted for thedegreeofDoctorofPhilosophy. Universityof London. 2010.

VAN EDE, Y. SesuousAnthropology: SenseandSensibilityandtheRehabilitationofSkill. Anthropological Notebooks, v. 15, n. 2, 2009, p. 61-75

v. No.()
$/ 2015$ ISSN 2237-8294 